\title{
A Single-Blind Randomized Controlled Trial Comparing the Efficacy of Two Doses of Oral Ibuprofen with Intravenous Indomethacin in Terms of Ductus Arteriosus Closure among Premature Infants with Patent Ductus Arteriosus: A Phase 2A Clinical Trial
}

\author{
Dexter D. Cheng, ${ }^{1}$ Edgardo E. Ortiz ${ }^{1}$ and James L. Angtuaco ${ }^{2}$ \\ ${ }^{1}$ Section of Pediatric Cardiology, Department of Pediatrics, College of Medicine and Philippine General Hospital, University of the Philippines Manila \\ ${ }^{2}$ Department of Pediatrics, Metropolitan Medical Center, Manila, Philippines
}

\begin{abstract}
Background and Objective. The incidence of Patent Ductus Arteriosus (PDA) in preterm infants ranges from $40 \%$ to $80 \%$, increasing with younger gestational age and lower birth weights. PDA is a common problem that leads to increased morbidity and mortality. Intravenous indomethacin has been the drug of choice for closure of hemodynamically significant PDA for many years. However, treatment with this non-steroidal antiinflammatory drug (NSAID) is associated with several side effects in neonates. Many researchers have been attempting to determine if other NSAID can be used in PDA closure. Currently, intravenous ibuprofen has been shown to close the ductus arteriosus with equal efficacy as intravenous indomethacin, but with fewer side effects. Since intravenous ibuprofen is not available in the local market, oral ibuprofen was investigated to determine if it will be efficacious in the closure of PDA. If proven effective in ductal closure in preterm infants, it will provide the preterm infant population with an economical and effective alternative form of therapy.
\end{abstract}

Study Design. This is a single blind randomized controlled phase $2 A$ trial.

Method. Thirty patients were enrolled in the study and randomly allocated to one of three groups: One group received indomethacin intravenously at doses of $0.2 \mathrm{mg} / \mathrm{kg}$ (day 1) then $0.1 \mathrm{mg} / \mathrm{kg}$ every 12 hours thereafter for 2 more doses. The second group received ibuprofen at a dose of $10 \mathrm{mg} / \mathrm{kg}$ every 12 hours for three doses per orem. The third group received ibuprofen at a $10 \mathrm{mg} / \mathrm{kg}$ initially, then $5 \mathrm{mg} / \mathrm{kg}$ every 12 hours for 2 doses per orem. All patients were treated on the $60^{\text {th }}-80^{\text {th }}$ hour of life. All patients had echocardiographic evidence of hemodynamically significant PDA. Repeat echocardiography was then repeated 24 hours and 7 days after the treatment intervention to assess if PDA closure was achieved. The echocardiographer was blinded to the treatment regimen.

Corresponding author: Dexter D. Cheng, MD

Department of Pediatrics

Philippine General Hospital

University of the Philippines Manila

Taft Avenue, Ermita, Manila 1000 Philippines

Telephone: +6325240892

Email: tmcmati808@gmail.com
Result. PDA closure was achieved in 6 of the 10 patients in the indomethacin group. The same results were obtained for the two doses of ibuprofen. There were no reported side effects in any of the patients treated.

Conclusion. Oral ibuprofen offers potential benefit in closing patent ductus arteriosus in preterm infants. Phase $2 \mathrm{~B}$ trial with a larger number of patients is recommended.

Key Words: Ibuprofen, indomethacin, patent ductus arteriosus

\section{Introduction}

The ductus arteriosus is a vascular channel that is vital to fetal circulation. However, its persistence after birth is often deleterious, most specially to premature infants. The ductus arteriosus connects the pulmonary artery to the descending aorta. Its function during fetal life is to divert most of the ventricular output from the lungs to the placenta. Postnatally, as the lungs assume respiratory gas exchange functions, right ventricular output must be redirected to flow through the pulmonary vascular bed. As such, the ductus arteriosus undergoes physiologic constriction. Normal postnatal ductal constriction results from a complex interaction between the precipitous reversals of relative pulmonary and systemic vascular resistances, from sudden variations in the levels of prostaglandins and other biochemical mediators, and from rapid increases in oxygenation of the blood.

Prostaglandins are potent vasoactive substances with extremely short half-lives. They are produced in exceedingly small quantities, and they have been found to be intimately involved in maintaining ductal patency in utero. Prostaglandin levels drop precipitously after birth, thereby facilitating spontaneous ductal constriction. Increased oxygen tension (PO2) is also a potent stimulator of ductal closure after birth and, conversely, hypoxia can precipitate or sustain ductal dilation. ${ }^{1}$

However, when infants are born prematurely, the normal mechanisms of ductal closure do not always function effectively. Alterations in the normal physiological shifts of 
these parameters are likely to impede spontaneous ductal closure, resulting in clinical signs consistent with persistent patency of the ductus arteriosus (PDA). ${ }^{1}$ In preterm infants, the PDA is a common problem that leads to increased morbidity and mortality. Several major sequelae include congestive heart failure, intraventricular hemorrhage, death of intestinal tissue known as necrotizing enterocolitis (NEC), bronchopulmonary dysplasia and even death. ${ }^{2}$

The incidence of patent ductus arteriosus (PDA) is inversely related to the gestational age and birth weight. It is estimated at $25 \%$ in those less than 33 weeks, ${ }^{3}$ and up to $40 \%$ of infants weighing less than $2000 \mathrm{gm}$ at birth and up to $80 \%$ of infants weighing less than $1200 \mathrm{gm}$ at birth. ${ }^{4}$ The overall incidence of persistent ductus arteriosus beyond the third day of life is $21 \% .^{2}$ Irrespective of age, patients with PDA require closure. Surgical closure of PDA has been shown to reduce neonatal morbidity but medical therapy has always been the first line treatment.

Since 1976, intravenous indomethacin, a non-selective cyclo-oxygenase inhibitor that inhibits the production of prostaglandins, has been the drug of choice for closure of hemodynamically significant PDA. Among preterm infants, intravenous indomethacin treatment produces closure in approximately $70-90 \%$ of patients. ${ }^{1}$ Several studies however, have illustrated the side effects associated with its use in neonates such as transient or permanent alteration in renal function, NEC, gastrointestinal hemorrhage, and impairment of cerebral blood flow. 1,3,5

Over recent years, ibuprofen, another nonselective cyclooxygenase inhibitor, has been shown to close the ductus arteriosus, but with fewer side effects than intravenous indomethacin. ${ }^{1,3,5,6}$ In 2000, a prospective trial by Van Overmeire showed data that suggested that early intravenous administration of three doses of ibuprofen in preterm neonates decreases prostaglandin levels and is effective in reducing the incidence of PDA and severity of respiratory status. Significant neurologic, intestinal, renal, hepatic or hematologic complications were not demonstrated. Since this initial trial, several papers have been published attesting to the safety and efficacy of ibuprofen as compared to indomethacin.5,6 The results of these early trials are encouraging and suggest that indomethacin may not be the best available drug for treating PDA in preterm infants. Unfortunately, almost all of these studies utilize both ibuprofen and indomethacin in the intravenous form.

A meta-analysis done by Ohlsson et al. in 2005, from the Cochrane review analyzing the benefits of intravenous indomethacin and ibuprofen found no statistically significant difference in the effectiveness of ibuprofen compared to indomethacin in closing the PDA. ${ }^{7}$ Over the past several years since 2005, there have been many papers suggesting that oral ibuprofen maybe effective in the closure of the preterm PDA. ${ }^{8,9}$
In our setting, intravenous indomethacin is not readily available to the general public and its expense poses a second limitation. Intravenous ibuprofen is likewise not available. However, ibuprofen is available as an oral suspension and its current use is as an analgesic and antipyretic.

This study determined the effect of two doses of oral ibuprofen compared to intravenous indomethacin in closing patent ductus arteriosus in preterm infants in a limited number of patients. If the study is found to have an effect similar to the control, bigger clinical trials will be pursued or recommended.

This study can support current evidence of finding an alternative medical therapy that can be offered to a larger percentage of the premature population that cannot afford intravenous indomethacin.

\section{Methods}

Thirty premature newborns that were delivered and treated at the neonatal intensive care unit at the Philippine General Hospital from August 2001 to July 2003 were recruited prospectively. The study was approved by the ethics committee (Committee on Research Implementation (CRID)) of the University of the Philippines, Manila. A written informed consent was obtained from the parents of each subject prior to enrollment into the study.

Premature infants were enrolled into the study when the following inclusion criteria were met: 1) pediatric aging between 26 and 36 weeks by Ballard score; 2) post-natal age between 60 and 80 hours; 3) echocardiographic evidence of significant PDA (left atrium/aortic root diameter ratio $>1.4$ or ductal size $>1.5 \mathrm{~mm}){ }^{10}$ and 4 ) started and has no contraindications to continued feeding. Neonates with major congenital malformations, persistent pulmonary hypertension, hydrops fetalis, ductus arteriosus dependent lesions, or in whom either indomethacin or ibuprofen are contraindicated were excluded. Contraindications for treatment with either drug included: 1) recent intraventricular hemorrhage documented by cranial ultrasonography; 2) clinical bleeding tendency (hematuria, blood on gastric aspirate or stools, oozing from venipuncture sites); 3) thrombocytopenia $\left.\left(<60,000 / \mathrm{mm}^{3}\right) ; 4\right)$ oliguria (urine output $<1 \mathrm{ml} / \mathrm{kg} / \mathrm{hr}$ ); 5) elevated BUN or creatinine levels; and 6) hyperbilirubinemia requiring exchange transfusion.

Standard color and 2D echocardiography (Esaote Biomedica, 1999, Genoa, Italy; $7 \mathrm{mHz}$ probe), based on AHA recommendations, was performed on all infants who were clinically suspected of having a PDA.

\section{Treatment Intervention}

Eligible patients were randomly assigned into 3 groups using a computer generated table of random numbers. One group received indomethacin (Indocin ${ }^{\circledR} \quad$ MSD) 
intravenously at a standard doses of $0.2 \mathrm{mg} / \mathrm{kg}$ (day 1 ) then $0.1 \mathrm{mg} / \mathrm{kg}$ every 12 hours thereafter $\times 2$ more doses (INDO). The second group received ibuprofen at a higher dose (Dolan ${ }^{\circledR}$ Pediatrica, Inc.) at a dose of $10 \mathrm{mg} / \mathrm{kg}$ every 12 hours for three doses per orem (IBU 10). The third group received ibuprofen at a lower dose of $10 \mathrm{mg} / \mathrm{kg}$ initially, then $5 \mathrm{mg} / \mathrm{kg}$ every 12 hours for 2 doses per orem (IBU 5).

The attending physician, who did not participate in the study and who was aware of the treatment protocol, performed routine daily clinical care. Echocardiography was conducted by a senior pediatric cardiologist who was unaware of the premature infant's treatment intervention. Echocardiography was repeated at 24 hours after the third dose and after one week to assess PDA closure. Birth weight, gestational age, and clinical outcome, including any side effects were recorded.

\section{Sample Size and Data Analysis}

A total of 30 patients were included in this study. Since this is a Phase 2A clinical trial, sample size computation for statistical power was not done. Continuous data are presented as mean \pm standard deviation. Other clinical data and outcome of ductal closure are recorded as a percentage in each group and were analyzed and compared using comparison of percentages, Chi-square, using Epi Info® version 6 . The difference in percentage of closure between the INDO group and IBU10, INDO group and IBU5, and IBU10 and IBU5 were estimated at 95\% confidence interval with adjustment for multiplicity. Intention to treat analysis (all patients with known outcomes were analyzed in the group to which they were randomized) was done to analyze the rates of PDA closure among the different interventions.

\section{Results}

The baseline characteristics of the 30 infants enrolled into the study are presented in Table 1 . There was no significant difference in the baseline characteristics of all groups with regard to age of gestation and birth weight.
There was likewise no difference in the manner of delivery, prior use of dexamethasone before delivery, or the degree of respiratory support following delivery (Table 1). The percentage of infants lost due to mortality was likewise not significant between groups.

The mortality rate was $30-40 \%$ among all groups. All subjects except for one from the indomethacin group were started on empiric antibiotic therapy. Antibiotics were continued based on clinical and blood culture results. The use of inotropes and furosemide during the care of the patients was not different among the three groups. The manner of respiratory support as a predictor of mortality was not significant. There were no reported side effects among all infants enrolled into the study with regard to intraventricular hemorrhage, decreased renal output, or hepatic effects. There was one patient who developed NEC four days after IBU 5 intake, but this was not clinically assessed to be secondary to the treatment intervention.

The causes of death are depicted in Figure 1. The causes were mainly due to sepsis neonatorum, respiratory failure due to pnuemothorax, and a combination of both these problems. Thus, these mortalities were not attributable to the therapy involved. This figure also shows the birth weights of the preterm infants who succumbed. There were seven patients enrolled into the study whose birth weights were less than 1000 grams. As depicted in Figure 1, six of these patients died. The case fatality rate of preterm infants whose birth weights were less than 1000 grams is $85-90 \%$, while those less than 1500 grams was $35-40 \%$, during the duration of the study.

The first 2D echocardiographic study showed slightly larger mean size of the ductus in the INDO group compared to the IBU groups but all 3 groups showed reduction in the size on the $2^{\text {nd }}$ and $3^{\text {rd }} 2 \mathrm{D}$ echocardiography compared to the first (Table 2). The rate of PDA closure was $60 \%$ in all 3 forms of therapy. Interval estimates of the differences between the groups crosses the null value of zero such that results at this point is inconclusive.

Table 1. Characteristics of patients diagnosed with Patent Ductus Arteriosus at the Department of Pediatrics - University of the Philippines-Philippine General Hospital

\begin{tabular}{|c|c|c|c|}
\hline Characteristic & $\begin{array}{l}\text { Indomethacin } \\
\text { (INDO) } \\
(\mathrm{N}=10)\end{array}$ & $\begin{array}{c}\text { Ibuprofen } 10 \mathrm{mg} / \mathrm{kg} \times 3 \text { doses } \\
\text { every } 12 \text { hours } \\
(\text { IBU 10) } \\
(\mathrm{N}=10)\end{array}$ & $\begin{array}{c}\text { Ibuprofen } 10 \mathrm{mg} / \mathrm{kg} \text { initially then } 5 \\
\mathrm{mg} / \mathrm{kg} \text {, all every } 12 \text { hours } \\
\text { (IBU 5) } \\
(\mathrm{N}=10)\end{array}$ \\
\hline $\begin{array}{l}\text { Birth weight, mean } \\
\text { (SD } \pm \text { grams) }\end{array}$ & $1435(\mathrm{SD} \pm 413$ grams $)$ & $1205(\mathrm{SD} \pm 448$ grams) & $1250(\mathrm{SD} \pm 321$ grams $)$ \\
\hline Age of Gestation, mean (SD \pm weeks) & 31.20 (SD \pm 2.2 weeks) & 31.10 (SD \pm 3.6 weeks) & $32.85(\mathrm{SD} \pm 2.2$ weeks $)$ \\
\hline \multicolumn{4}{|l|}{ Mode of Delivery, \% } \\
\hline SVD & $40 \%$ & $40 \%$ & $50 \%$ \\
\hline Caesarian Section & $60 \%$ & $60 \%$ & $50 \%$ \\
\hline Dexamethasone prior to delivery given, $\%$ & $0 \%$ & $30 \%$ & $30 \%$ \\
\hline \multicolumn{4}{|l|}{ Intervention Done, $\%$} \\
\hline Oxygen hood & $40 \%$ & $50 \%$ & $40 \%$ \\
\hline Intubated & $60 \%$ & $50 \%$ & $60 \%$ \\
\hline \multicolumn{4}{|l|}{ Clinical Outcome, \% } \\
\hline Mortality & $40 \%$ & $40 \%$ & $30 \%$ \\
\hline
\end{tabular}


Table 2. Comparison of PDA size by 2D-Echocardiography results of patients born at the Department of Pediatrics University of the Philippines-Philippine General Hospital

\begin{tabular}{|c|c|c|c|c|}
\hline Characteristic & $\begin{array}{l}\text { Indomethacin } \\
\text { (INDO) } \\
(\mathrm{N}=10)\end{array}$ & $\begin{array}{c}\text { Ibuprofen } 10 \mathrm{mg} / \mathrm{kg} \times 3 \\
\text { doses every } 12 \text { hours } \\
\text { (IBU 10) } \\
(\mathrm{N}=10)\end{array}$ & $\begin{array}{l}\text { Ibuprofen } 10 \mathrm{mg} / \mathrm{kg} \text { initially } \\
\text { then } 5 \mathrm{mg} / \mathrm{kg} \text {, all every } 12 \text { hours } \\
\text { (IBU 5) } \\
(\mathrm{N}=10)\end{array}$ & p-value \\
\hline \multicolumn{5}{|c|}{ PDA size, mean $( \pm \mathrm{SD})(\mathrm{ITT})^{* *}$} \\
\hline First echo & $2.82(\mathrm{SD} \pm 0.94)$ & $2.14(\mathrm{SD} \pm 0.45)$ & $2.04(\mathrm{SD} \pm 0.39)$ & \\
\hline Second echo & $0.95(\mathrm{SD} \pm 1.29)$ & $0.22(\mathrm{SD} \pm 0.63)$ & $0.57(\mathrm{SD} \pm 0.79)$ & \\
\hline Third echo & $0.17(\mathrm{SD} \pm 0.41)$ & $0.22(\mathrm{SD} \pm 0.53)$ & $0.43(\mathrm{SD} \pm 1.13)$ & \\
\hline \multicolumn{5}{|l|}{ PDA closure, $\%$} \\
\hline By second 2D echo & $50 \%(5)$ & $70 \%(7)$ & $50 \%(5)$ & \\
\hline By third 2D echo & $60 \%(6)$ & $60 \%(6)$ & $60 \%(6)$ & $1.000^{*}$ \\
\hline \multicolumn{5}{|l|}{ Pairwise Comparisons*** } \\
\hline INDO-IBU10 & $0(-52,52)$ & & & \\
\hline INDO-IBU 5 & $0(-52,52)$ & & & \\
\hline IBU 10-IBU 5 & $0(-52,52)$ & & & \\
\hline
\end{tabular}

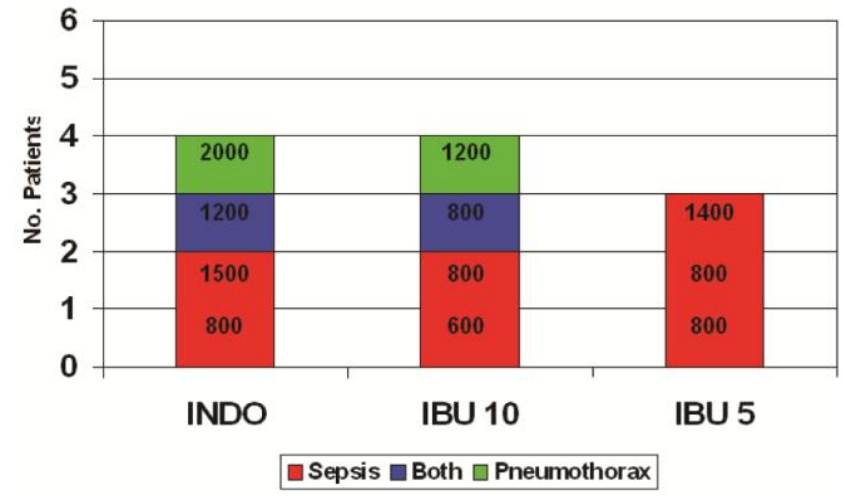

Figure 1. Cause of death among the different treatment interventions. Birth weights in grams of each of these patients are indicated.

Figure 2 shows the distribution of patients with regard to PDA closure. There was note of one patient in the IBU 10 group with re-opening of the ductus one week after treatment. This was, however, not a significant PDA and which had closed on prolonged follow up of 30 days. There were two patients in the IBU 5 group that failed to close. The size of the ductus in these two patients was not clinically significant and did not warrant further intervention.

\section{Discussion}

It is well known that patent ductus arteriosus remains to be a frequent problem in premature infants especially if associated with respiratory distress syndrome. Clinical symptoms of PDA in preterm newborns are variable, ranging from asymptomatic to complete cardiovascular collapse. Findings may include a murmur, tachycardia, bounding peripheral pulses, hyperactive precordium, apnea, and deterioration of respiratory status. ${ }^{4}$

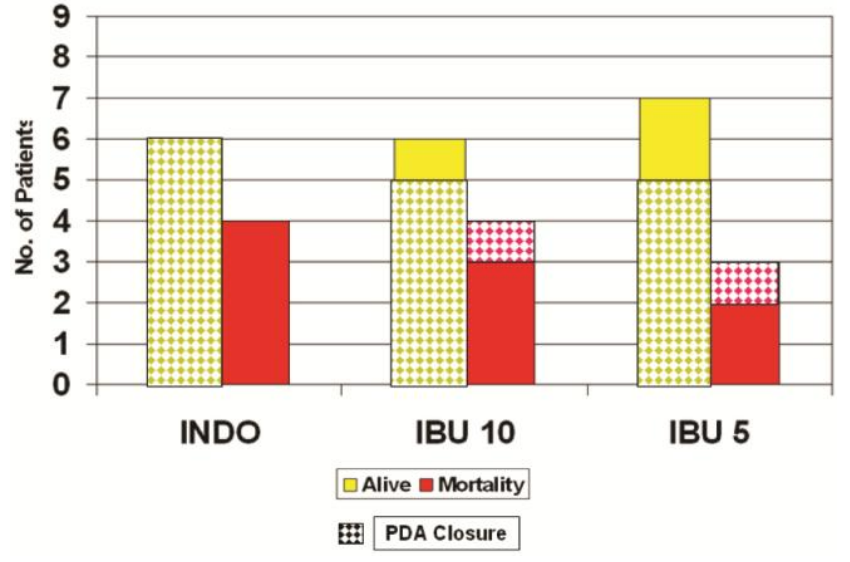

Figure 2. Distribution of successful PDA closure among the different treatment interventions and classified according to whether they survived to discharge.

In full-term infants, closure of the ductus occurs in two phases: smooth-muscle constriction produces "functional" closure of the lumen of the ductus within hours after birth, and "anatomical" occlusion of the lumen occurs over the next several days owing to extensive neointimal thickening and loss of smooth-muscle cells from the inner muscle media. ${ }^{11}$ The loss of luminal blood flow produces a zone of hypoxia in the muscle media of the ductus that appears to be the necessary signal for irreversible anatomical closure. ${ }^{12}$ Prostaglandins are vasoactive substances, which are involved in maintaining ductal patency in utero. After delivery, the levels of prostaglandin drop significantly and, thus, facilitate 'functional closure' of the ductus. Likewise, increased oxygen tension is also a potent stimulus for ductal closure. In preterm infants, however, the normal mechanisms of ductal closure do not always function effectively. One mechanism that promotes ductal patency is 
due to the increased sensitivity of the immature ductus to the vasodilating effects of prostaglandin.

Indomethacin is a nonselective cyclooxygenase inhibitor that inhibits the production of prostaglandin E, and thus promotes ductal closure. Although intravenous indomethacin is the standard of care, it is associated with adverse effects that are predominantly mediated by the vasoconstriction of various vascular beds: renal, cerebral, and gastro-intestinal. Intravenous ibuprofen, on the other hand, has been shown to be equally effective in ductal closure but with significantly less side effects compared to indomethacin. ${ }^{13}$ There are several reports of oral ibuprofen use in the treatment of PDA in preterm infants but many are not randomized. A systematic review and meta-analysis was done by Neumann in 2012 with two studies with good methodological quality and a combined sample of 166 . The review concluded that oral ibuprofen appears as effective as IV ibuprofen and IV Indomethacin. ${ }^{8}$ The treatment with oral ibuprofen would provide several advantages if proven effective. These benefits would include widespread availability, simple administration, and decreased cost. ${ }^{14}$

Our results showed a ductal closure rate of $60 \%$ for both intravenous indomethacin and the two doses of oral ibuprofen. There were no reported side effects among all enrolled subjects. The single patient that developed NEC four days after ibuprofen intake was being treated for sepsis and the NEC was considered part of the clinical manifestations of sepsis.

There were 11 mortalities in this study. The causes of death were either from sepsis, respiratory compromise, or a combination of both. Of the seven patients with birth weights less than 1000 gram enrolled into the study, six of these infants died of sepsis. The single survivor was oxygen dependent at 30 days of life and whose PDA had closed. There is no indication that the administration of either indomethacin intravenously or oral ibuprofen contributed to the cause of mortality. However, due to the increased drop out of subjects due to mortality secondary to sepsis and to the small sample size, definite conclusions cannot be drawn from this study. In order to further elucidate the safety and efficacy of such therapy, further study involving a larger sample size from multiple centers will be necessary.

\section{Conclusion}

The results suggest that oral ibuprofen may be an effective therapy in closing patent ductus arteriosus in preterm infants. A study with a larger sample size is needed to better elucidate these findings.

\section{Acknowledgments}

Pediatrica, Inc., a division of United Laboratories, Philippines, for providing the drug Ibuprofen (Dolan) used in the study.

\section{References}

1. Hammerman C, Kaplan M. Comparative tolerability of pharmacologic treatments for patent ductus arteriosus. Drug Saf. 2001; 24(7):537-51.

2. Siassi B, Blanco C, Cabal LA, Coran AG. Incidence and clinical features of patent ductus arteriosus in low-birthweight infants: a prospective analysis of 150 consecutively born infants. Pediatrics. 1976; 57(3):347-51.

3. Keady S, Grosso A. Ibuprofen in the management of neonatal patent ductus arteriosus. Intensive Crit Care Nurs. 2005; 21(1):56-8.

4. Ellison RC, Peckham GJ, Lang P, et al. Evaluation of the preterm infant for patent ductus arteriosus. Pediatrics. 1983; 71(3):364-72.

5. Su PH, Chen JY, Su CM, Huang TC, Lee HS. Comparison of ibuprofen and indomethacin therapy for patent ductus arteriosus in preterm infants. Pediatr Int. 2003; 45(6):665-70.

6. Lago P, Bettiol T, Salvadori S, et al. Safety and efficacy of ibuprofen versus indomethacin in preterm infants treated for patent ductus arteriosus: a randomized controlled trial. Eur J Pediatr. 2002; 161(4):202-

7. Ohlsson A, Walia R, Shah S. Ibuprofen for the treatment of patent ductus arteriosus in preterm and/or low birth weight infants. Cochrane Database Syst Rev. 2005; (4):CD003481.

8. Neumann R, Schulzke SM, Buhrer C. Oral ibuprofen versus intravenous ibuprofen or intravenous Indomethacin for the treatment of patent ductus arteriosus in preterm infants: a systematic review and metaanalysis. Neonatology. 2012; 102(1):9-15.

9. Erdeve O,Yurttutan S, Altug N, et al. Oral versus intravenous ibuprofen for patent ductus arteriosus closure: a randomized controlled trial in extremely low birthweight infants. Arch Dis Child Fetal Neonatal Ed. 2012; 97(4):F279-83.

10. Johnson GL, Breart GL, Gewitz MH, et al. Echocardiographic characteristics of premature infants with patent ductus arteriosus. Pediatrics. 1983; 72(6):864-71.

11. Clyman RI. Ibuprofen and patent ductus arteriosus. N Engl J Med. 2000; 343(10):728-30.

12. Clyman RI, Chan CY, Mauray F, et al. Permanent anatomic closure of the ductus arteriosus in newborn baboons: the roles of postnatal constriction, hypoxia, and gestation. Pediatr Res. 1999; 45(1):19-29.

13. Van Overmeire B, Smets K, Lecoutere D, et al. A comparison of ibuprofen and indomethacin for closure of patent ductus arteriosus. N Engl J Med. 2000; 343(10):674-81.

14. Hariprasad P, Sundarrajan V, Srimathy G, Suthagar B, Ramadevi BS. Oral ibuprofen for closure of hemodynamically significant PDA in premature neonates. Indian Pediatr. 2002; 39(1):99-100. 